ARTICLE

\title{
Total synthesis of tetraacylated
}

phosphatidylinositol hexamannoside and evaluation of its immunomodulatory activity

\author{
Pratap S. Patil ${ }^{1}$, Ting-Jen Rachel Cheng ${ }^{1}$, Medel Manuel L. Zulueta ${ }^{1}$, Shih-Ting Yang ${ }^{1}$, \\ Larry S. Lico ${ }^{1} \&$ Shang-Cheng Hung ${ }^{1}$
}

Tuberculosis, aggravated by drug-resistant strains and HIV co-infection of the causative agent Mycobacterium tuberculosis, is a global problem that affects millions of people. With essential immunoregulatory roles, phosphatidylinositol mannosides are among the cell-envelope components critical to the pathogenesis and survival of $M$. tuberculosis inside its host. Here we report the first synthesis of the highly complex tetraacylated phosphatidylinositol hexamannoside $\left(\mathrm{Ac}_{2} \mathrm{PIM}_{6}\right)$, having stearic and tuberculostearic acids as lipid components. Our effort makes use of stereoelectronic and steric effects to control the regioselective and stereoselective outcomes and minimize the synthetic steps, particularly in the key desymmetrization and functionalization of myo-inositol. A short synthesis of tuberculostearic acid in six steps from the Roche ester is also described. Mice exposed to the synthesized $\mathrm{Ac}_{2} \mathrm{PIM}_{6}$ exhibit increased production of interleukin- 4 and interferon- $\gamma$, and the corresponding adjuvant effect is shown by the induction of ovalbumin- and tetanus toxoid-specific antibodies.

\footnotetext{
${ }^{1}$ Genomics Research Center, Academia Sinica, No. 128, Section 2, Academia Road, Taipei 115, Taiwan. Correspondence and requests for materials should be addressed to S.-C.H. (email: schung@gate.sinica.edu.tw).
} 
M ycobacterium tuberculosis is a dreaded pathogen that causes tuberculosis, one of the leading causes of death in the world. Although the disease becomes active for only $5-10 \%$ of infected individuals, 1.5 million people died of tuberculosis in 2013 alone despite progress in the global effort for diagnosis, treatment and prevention ${ }^{1}$. Moreover, it is estimated that one-third of the human population is latently infected with M. tuberculosis and is highly vulnerable if immunocompromised. The antituberculosis vaccine bacillus Calmette-Guérin, made by using an attenuated strain of $M$. bovis, only gives protection to children but is highly variable in adults ${ }^{2}$. Co-infection with HIV and the rising cases of multidrug and extensive drug resistance also add to the high morbidity and mortality of the disease ${ }^{3}$. Clearly, fresh insights on the character of the causative agent and its pathogenesis are needed to help alleviate this human condition $^{4}$.

The thick glycolipid-containing cell envelope $\mathrm{e}^{5}$ of $M$. tuberculosis is critical for bacterial survival and growth. It is involved in sabotaging immunoregulatory responses ${ }^{6-8}$ and it forms a protective barrier for various drugs 9,10 . Among the vital cellenvelope components, phosphatidylinositol mannosides (PIMs) and their hypermannosylated structural relatives (lipomannans and lipoarabinomannans) are found noncovalently anchored to the plasma membrane and the outer capsule through palmitate, stearate and tuberculostearate lipid chains ${ }^{11}$. PIMs, in particular, dictate the intercellular fate of mycobacteria by binding to macrophages ${ }^{12}$, regulate cytokines and reactive radical species and stimulate early endosomal fusion by acting as ligands to Tolllike receptors, C-type lectins and DC-SIGN ${ }^{13}$. PIMs can also act as CD1d antigen to activate natural killer $\mathrm{T}$ cells for the production of interferon- $\gamma$ (ref. 14), indicating their potential as vaccine or adjuvant candidates. In addition, PIMs interact with $\alpha_{5} \beta_{1}$ integrin on $\mathrm{CD}^{+}$lymphocytes, which can either promote granuloma formation and enhance host immune response or help in bacterial survival $^{15}$

Structurally, myo-inositol is the central support unit of PIMs with a diacylated glycerophospholipid moiety at $\mathrm{O} 1$ and $\alpha$-mannosylation sites at O2 and O6 (ref. 16). Additional lipid chains may be linked at the primary hydroxyl of the 2-O-mannosyl unit and at the $\mathrm{O} 3$ position of myo-inositol to form triacylated PIMs (AcPIMs) and tetraacylated PIMs ( $\left.\mathrm{Ac}_{2} \mathrm{PIMs}\right)$, respectively.
Higher PIMs (for example, $\mathrm{Ac}_{n} \mathrm{PIM}_{3}-\mathrm{Ac}_{n} \mathrm{PIM}_{6}$ ) are formed by elongation at the mannose residue linked at $\mathrm{O} 6$ of myo-inositol. The number of mannose residues and the degree and type of the fatty acyl groups present in the PIM molecules determine their unique role in immunoregulation ${ }^{11}$. As a result, elegant synthetic strategies have been developed for PIMs and their related compounds ${ }^{17-34}$. Nevertheless, the synthesis of a tetraacylated phosphatidylinositol hexamannoside $\left(\mathrm{Ac}_{2} \mathrm{PIM}_{6}\right)$, the most complex among this class of compounds, is yet to be reported. Thus far, previous disclosures explored the synthesis of $\mathrm{Ac}_{2} \mathrm{PIM}_{2}$ (ref. 34), $\mathrm{PIM}_{4}$ (ref. 24), $\mathrm{PIM}_{6}$ (ref. 32) and $\mathrm{AcPIM}_{6}$ (ref. 25) to name a few.

We describe herein the first synthesis of $\mathrm{Ac}_{2} \mathrm{PIM}_{6}$, using stearic and tuberculostearic acids as the lipid components. The immunomodulatory activity of the synthesized $\mathrm{Ac}_{2} \mathrm{PIM}_{6}$ was also evaluated.

\section{Results}

Synthetic strategy. Compound 1 possesses multiple components and functionalizations. To arrive at this molecule, one rational synthetic design would be to fragment this sizeable structure into separate segments, which could later be assembled in a convergent manner. For this purpose, we conceived the pseudotrisaccharide 2, tetramannoside donor $\mathbf{3}$ and phosphonate $\mathbf{4}$ as the primary targets (Fig. 1). The readily perceptible synthetic issues include the transformation of the ordinarily meso myoinositol into the unsymmetrical counterpart in $\mathbf{2}$ as well as the regioselective protection to afford the mannosyl-building blocks useful enough to deliver the necessary $\alpha 1 \rightarrow 2$ and $\alpha 1 \rightarrow 6$ linkages and the acylation of one mannosyl unit. Accordingly, along with benzyl groups for the global protection of hydroxyls that would be free in the desired product, we selected two additional orthogonal protecting groups for the primary positions of the mannosyl residues in intermediates leading to compound 2 . The tert-butyldiphenylsilyl (TBDPS) group should allow, on deprotection, the subsequent coupling with the tetramannoside $\mathbf{3}$, whereas the 2-naphthylmethyl (2-NAP) group protects the position that would later be acylated. Being a core constituent of inositol phosphates and other phosphatidyl lipoglycans, various methods have been published for the myo-inositol resolution and
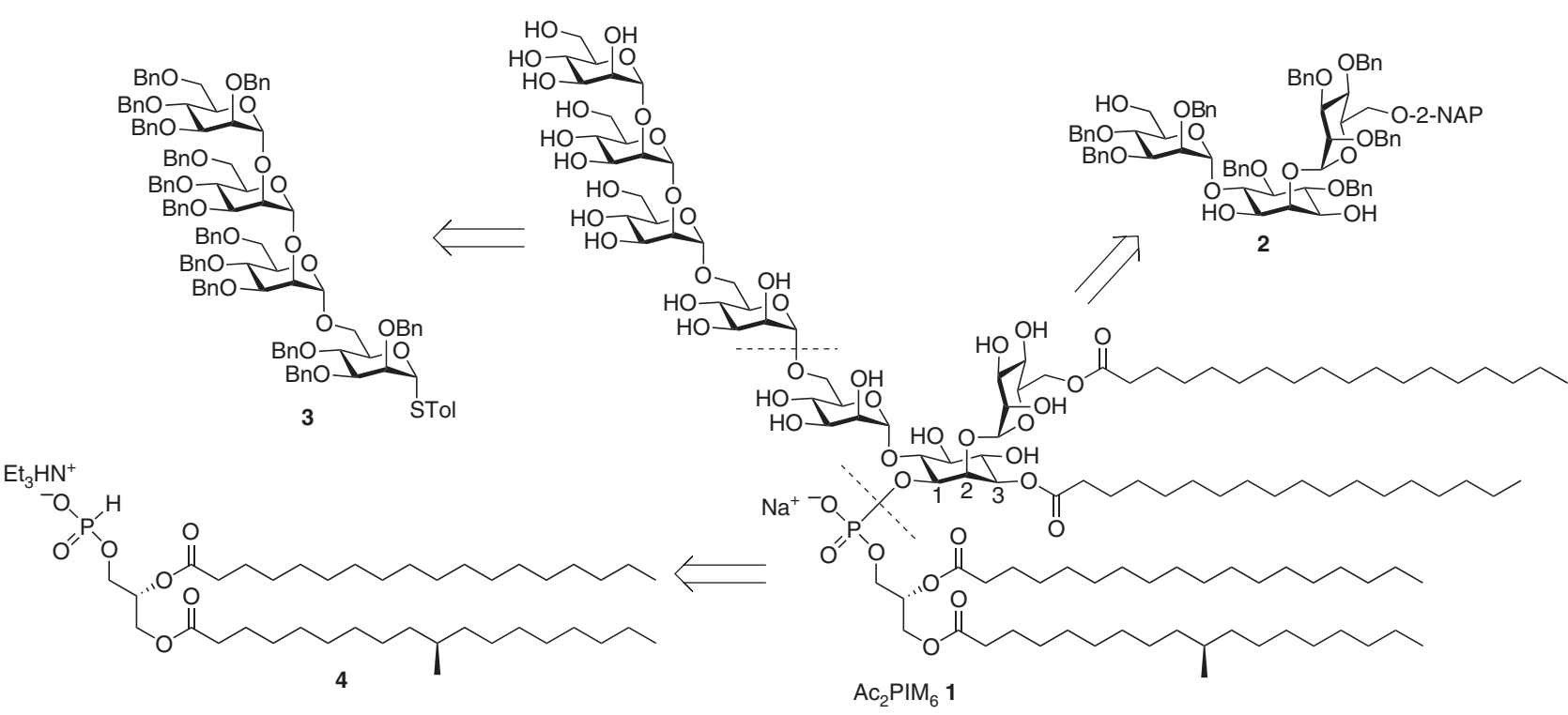

Figure 1 | Our target tetraacylated phosphatidylinositol hexamannoside $\left(\mathrm{Ac}_{2} \mathrm{PIM}_{6}\right)$ and the main blocks designed to represent each segment. 2-NAP, 2-naphthylmethyl; Bn, benzyl; Tol, p-tolyl. 
desymmetrization ${ }^{35,36}$. However, the suitably protected chiral myo-inositol derivative required for PIMs and glycosyl phosphatidylinositide synthesis were mainly achieved through multistep synthesis from $\mathrm{D}$-glucose via the Ferrier reaction ${ }^{37}$. Recently, we have shown that a mannosyl donor can directly act as chiral auxiliary to differentiate the enantiotopic hydroxyls of meso myo-inositol derivatives ${ }^{30,31}$. This direct approach bypasses many transformation steps in affording an appropriately mannosylated and desymmetrized myo-inositol. We intend to apply this capacity towards diol $\mathbf{2}$ while also relying on the steric hindrance created by the installed mannosyl residues to strategically position the 4,5-di-O-benzyl moieties on the myoinositol unit and sufficiently favour regioselective acylation at the free 3-OH. An extra temporary protecting group and participating moiety is also needed to permit the construction of the tetramannoside 3 , in which case we chose a 2-O-benzoyl group. We planned to assemble 3 through linear glycosylation from the reducing end to the nonreducing end using a single elongation unit. For the phosphonate $\mathbf{4}$, access to the rare tuberculostearic acid is the main concern, and this fatty acid should be synthesized to complete the desired phospholipid moiety.

Mannosyl-building blocks. Considering the stability of the thiotolyl leaving group on various functional group interconversions, we selected the thiomannoside $\mathbf{5}$ (ref. 38) as a starting point in our transformations towards several mannosyl building blocks (Fig. 2). In general, the building blocks needed for the assembly of our target structure required differentiation at either $\mathrm{O} 6$ or O2. With a bulky functionality such as the TBDPS group, the protection sequence aimed regioselectively at the primary $\mathrm{O} 6$ position seems clear-cut. Thus, the 6-O-silylation of 5 using tert-butyldiphenylchlorosilane, triethylamine and 4-(N,N-dimethylamino)pyridine gave compound $\mathbf{6}$ in excellent yield. Subsequent benzylation under Williamson condition supplied the necessary thioglycoside 7 . The 6-alcohol $\mathbf{8}$, intended as the starting acceptor in generating the tetramannoside $\mathbf{3}$, was also readily acquired from 7 by acidic desilylation.

In contrast to the route above, traditional approaches concerning the effective acquisitions of the 6-O-naphthylmethylated thiomannoside 13 and the 2-benzoate 14 do not appear to be straightforward. The complexity arises from the desire to carry out the fully regioselective installations of the vital ether groups. Apparently, the regioselective one-pot protection strategy that we introduced 39,40 and further expanded to other sugars ${ }^{41-44}$ could simplify such preparations. Our recent work on the stereoselective dioxolane-type benzylidene formation on thiomannosides ${ }^{43}$ should provide a convenient gateway to the 2,6-diol 11, a potential common intermediate towards compounds 13 and 14. It was envisioned that, with benzyl groups permanently protecting $\mathrm{O} 3$ and $\mathrm{O} 4$, the

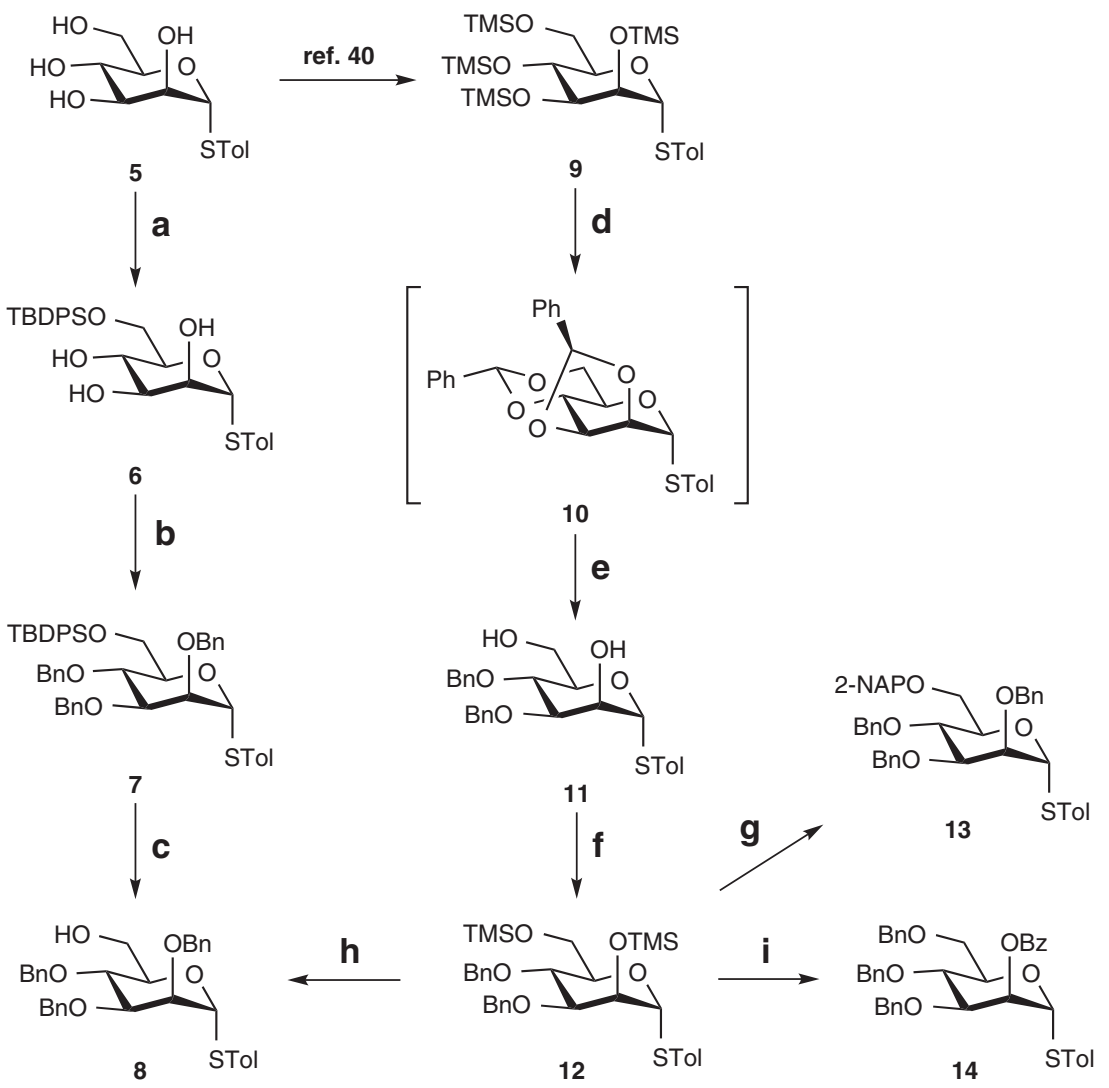

Figure 2 | Preparations of the mannosyl-building blocks. Reagents and conditions: (a) tert-butyldiphenylchlorosilane, $\mathrm{Et}_{3} \mathrm{~N}, \mathrm{DMAP}, 93 \%$; $(\mathbf{b}) \mathrm{NaH}, \mathrm{BnBr}_{4}$ DMF, 94\%; (c) PTSA, MeOH, $\mathrm{CH}_{2} \mathrm{Cl}_{2}, 92 \%$; (d) benzaldehyde (2.1 equivalents), TMSOTf, $\mathrm{MeCN}, \mathrm{O}^{\circ} \mathrm{C}, 30$ min; (e) $\mathrm{BH}_{3} \cdot \mathrm{THF}_{1} \mathrm{Cu}\left(\mathrm{OTf}\right.$ ) $2, \mathrm{CH}_{2} \mathrm{Cl}_{2}, 87 \%$ (one pot from 9); (f) trimethylchlorosilane, $\mathrm{Et}_{3} \mathrm{~N}$, quantitative; (g) 2-naphthaldehyde, $\mathrm{Et}_{3} \mathrm{SiH}, \mathrm{TMSOTf} \mathrm{CH}_{2} \mathrm{Cl}_{2},-78$ to $-40^{\circ} \mathrm{C}, 2 \mathrm{~h}, \mathrm{then}, \mathrm{NaH}, \mathrm{BnBr}, \mathrm{DMF}, 81 \%$ (one pot); (h) 2-naphthaldehyde, $\mathrm{Et}_{3} \mathrm{SiH}, \mathrm{TMSOTf}, \mathrm{CH}_{2} \mathrm{Cl}_{2},-78$ to $-40{ }^{\circ} \mathrm{C}, 2 \mathrm{~h}$, then, $\mathrm{NaH}, \mathrm{BnBr}$, DMF, then, DDQ, $\mathrm{H}_{2} \mathrm{O}, 73 \%$ (one pot); (i) benzaldehyde, $\mathrm{Et}_{3} \mathrm{SiH}$, TMSOTf, $-78{ }^{\circ} \mathrm{C}, 1.5 \mathrm{~h}$, then, $\mathrm{BF}_{3} \cdot \mathrm{Et}_{2} \mathrm{O}, \mathrm{MeCN}$, -78 to $-20^{\circ} \mathrm{C}, 30 \mathrm{~min}$, then, $\mathrm{Bz}_{2} \mathrm{O}, \mathrm{Et}_{3} \mathrm{~N}, 93 \%$ (one pot). $\mathrm{Bz}$, benzoyl; $\mathrm{Bz}_{2} \mathrm{O}$, benzoic anhydride; $\mathrm{Cu}(\mathrm{OTf})_{2}$, copper(II) trifluoromethanesulfonate; DDQ, 2,3-dichloro-5,6-dicyano-1,4-benzoquinone; DMAP, 4-(N,N-dimethylamino)pyridine; DMF, $\mathrm{N}, \mathrm{N}$-dimethylformamide; Ph, phenyl; PTSA, $p$-toluenesulfonic acid; TBDPS, tert-butyldiphenylsilyl; THF, tetrahydrofuran; TMS, trimethylsilyl, TMSOTf, trimethylsilyl trifluoromethanesulfonate. 
primary 6-hydroxyl could be easily differentiated from the secondary and axial 2-hydroxyl. We were also keen to check whether stereoselective dibenzylidenation and simultaneous regioselective ring opening could be achieved in one pot.

Starting from the tetrakis-trimethylsilyl ether 9 acquired in one step from 5 (ref. 43), treatment with 2.1 equivalents of benzaldehyde along with catalytic trimethylsilyl trifluoromethanesulfonate (TMSOTf) in acetonitrile at $0{ }^{\circ} \mathrm{C}$ exclusively delivered the exo-product $\mathbf{1 0}$ as evidenced by NMR spectroscopy and X-ray crystallography (Supplementary Fig. 1, Supplementary Data 1). This fully stereoselective transformation is beneficial because unlike the regioselectivity in the 4,6-O-benzylidene ring opening, which is determined by the choice of reducing agent ${ }^{45}$, the opening of the dioxolane-type 2,3-O-benzylidine moiety is guided by the orientation of the phenyl group (that is, exo-isomers generally open at the axial position). Delightfully, the subsequent exposure of 10 to $\mathrm{BH}_{3}$. tetrahydrofuran in the same vessel provided the diol 11 in a two-stage one-pot yield of $87 \%$. Anticipating a smooth regioselective reductive etherification at O6 (ref. 46), we subjected the diol 11 to trimethylsilylation. Consequently, treatment of the so-formed $\mathbf{1 2}$ with 2-naphthaldehyde, triethylsilane and TMSOTf in subzero temperature supplied the intermediate that was benzylated in one pot using the typical etherification method to afford compound 13. An X-ray single crystal analysis fully supported the desired structure (Supplementary Fig. 1,
Supplementary Data 2). Continuing further, addition of 2,3-dichloro-5,6-dicyano-1,4-benzoquinone to the in situgenerated 13 successfully delivered the same acceptor 8, thus providing an alternative pathway for its acquisition. Similarly, the corresponding reductive 6-O-benzylation of 12 was carried out, followed by desilylation at $\mathrm{O} 2$ with tetrabutylammonium fluoride (TBAF) and basic benzoylation in the same flask. Unfortunately, the yield for compound $\mathbf{1 4}$ was less than satisfactory even when benzoic acid and TBAF were used together ${ }^{41}$ to perform the desilylation, probably due to the interference of TBAF to the benzoylation stage. Desilylation with $\mathrm{BF}_{3} \cdot \mathrm{Et}_{2} \mathrm{O}$ apparently solved this issue and furnished $\mathbf{1 4}$ in an excellent 93\% yield from $\mathbf{1 2}$.

Synthesis of the pseudotrisaccharide 2. For the desymmetrization of myo-inositol, we evaluated the coupling of the mannosyl donor 7 with the meso diol 16 (Fig. 3), which can be easily prepared in one step $^{30}$ from the commercially available Kishi's triol. The asymmetric nature of the mannosyl donor itself should provide certain preferences between the axial hydroxyls of $\mathbf{1 6}$ as we have demonstrated previously ${ }^{30}$ but without the TBDPS group on the sugar. Because of the wider opening available for a nucleophilic attack on the half-chair mannosyl oxocarbenium ion intermediate by $\mathrm{O} 6$ as compared with O4 (Supplementary Fig. 2), it is expected that the required 6-O-mannosylation would be more favoured. Our attempts at coupling of 7 and 16 using

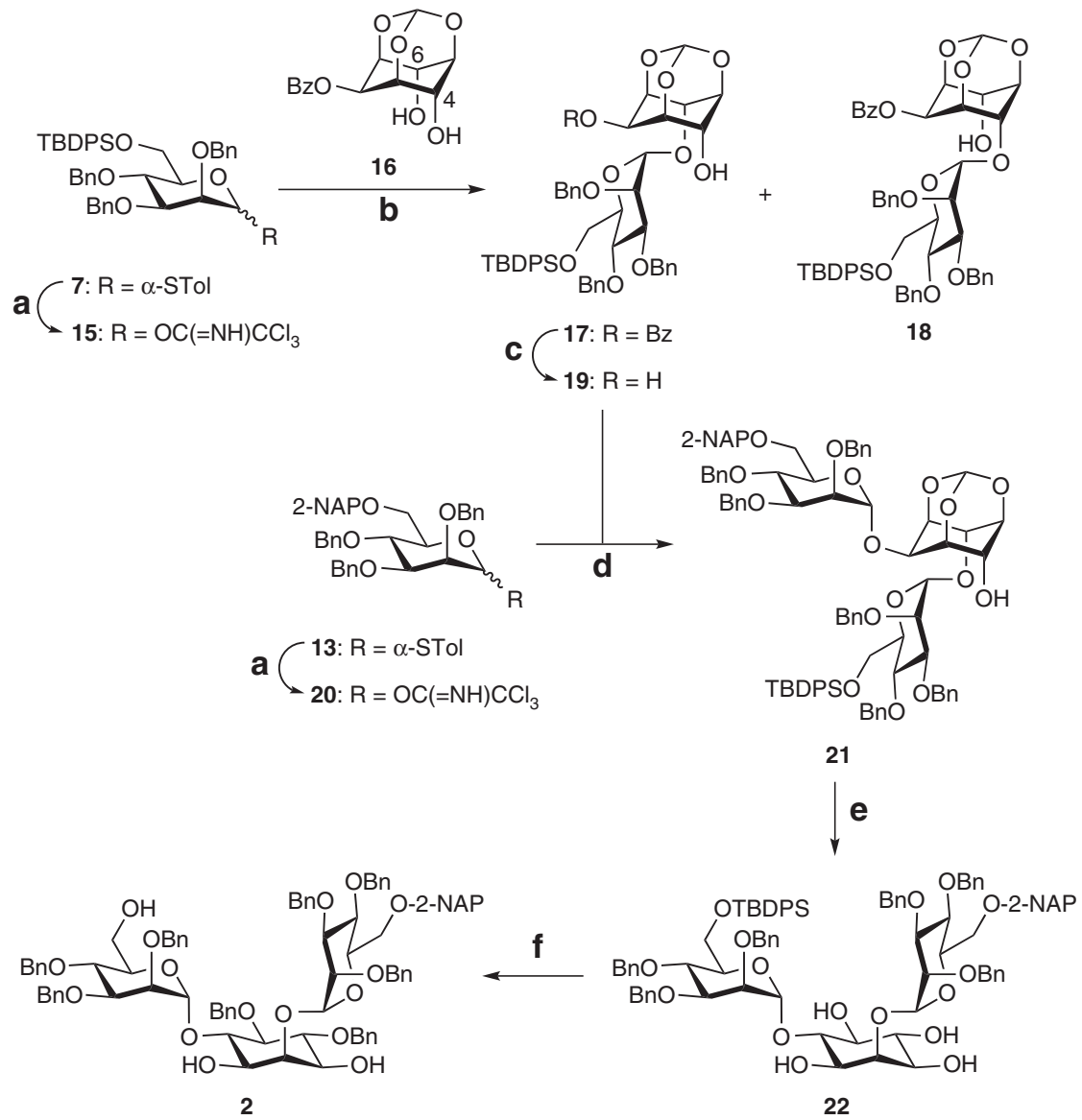

Figure 3 | Preparation of the pseudotrisaccharide 2. Reagents and conditions: (a) (1) NBS, acetone, $\mathrm{H}_{2} \mathrm{O}$; (2) $\mathrm{K}_{2} \mathrm{CO}_{3}, \mathrm{CCl}_{3} \mathrm{CN}_{1}$ 15: $94 \%$ (two steps), 20: $90 \%$ (two steps); (b) silver trifluoromethanesulfonate, 1,4-dioxane, $\mathrm{CH}_{2} \mathrm{Cl}_{2}$, 17: 68\%, 18: 20\%; (c) $\mathrm{NaOMe}, \mathrm{MeOH} \mathrm{CH}_{2} \mathrm{Cl}_{2}$, quantitative; (d) $\mathrm{BF}_{3} \cdot \mathrm{Et}_{2} \mathrm{O}, \mathrm{CH}_{2} \mathrm{Cl}_{2},-60$ to $-20^{\circ} \mathrm{C}, 72 \%$; (e) (1) $\mathrm{PTSA}, \mathrm{MeOH}, \mathrm{CH}_{2} \mathrm{Cl}_{2}, 84 \%$; (2) tert-butyldiphenylchlorosilane, Et ${ }_{3} \mathrm{~N}, \mathrm{DMAP}, 82 \%$; (f) (1) trimethylchlorosilane, $\mathrm{Et}_{3} \mathrm{~N}$, quantitative; (2) benzaldehyde ( 3 equivalent), $\mathrm{Et}_{3} \mathrm{SiH}, \mathrm{TMSOTf}, \mathrm{CH}_{2} \mathrm{Cl}_{2},-40{ }^{\circ} \mathrm{C}$, then, tetrabutylammonium fluoride, $72 \%$. NBS, $N$-bromosuccinimide. 
$\mathrm{N}$-iodosuccinimide and TMSOTf in $\mathrm{CH}_{2} \mathrm{Cl}_{2}$ and 1,4-dioxane to improve the solubility of diol 16, unfortunately, led only to donor hydrolysis and full recovery of the acceptor. We suspected that the axial hydroxyls are too unreactive for mannosyl thioglycoside to foster productive couplings. With strong activators avoided to maintain the acid-sensitive orthoformate group, focus was shifted to the imidate versions of the donor. After some optimization (see the Supplementary Table 1), silver trifluoromethanesulfonate promoted the glycosylation step at room temperature, supplying the desired pseudodisaccharide $\mathbf{1 7}$ at $68 \%$ yield, along with its regioisomer $18(20 \%)$. Here and in the succeeding glycosylations, we verified the $\alpha$-orientations of the mannosidic bonds through the coupling constants of the anomeric carbons and protons $(\sim 170 \mathrm{~Hz} \text {, see Supplementary Methods })^{47,48}$. Distinguishing the structures of $\mathbf{1 7}$ and 18 with confidence is not possible with NMR analysis alone. We, therefore, resorted to exchange the primary TBDPS with benzyl group (Supplementary Fig. 3) and compare agreement with the NMR spectra from previously published data $^{30}$

For the preparation of the key intermediate 21 , the pseudodisaccharide $\mathbf{1 7}$ was subjected to Zemplén deacylation to generate the diol 19. Regioselective mannosylation at the equatorial hydroxy group should be more likely because of steric reasons. A thorough evaluation of the subsequent coupling also made us consider the application of the imidate $\mathbf{2 0}$ over the thioglycoside 13. Under $\mathrm{BF}_{3} \cdot \mathrm{Et}_{2} \mathrm{O}$ promotion, compound 21 was, therefore, acquired in $72 \%$ yield with complete regioselectivity and stereoselectivity. The orthoformate group was cleaved using $p$-toluenesulfonic acid, which also removed the TBDPS group. The tetraol $\mathbf{2 2}$ was obtained after re-installation of the silyl group. With 22 in hand, regioselective benzylation at $\mathrm{O} 4$ and $\mathrm{O} 5$ of the inositol unit is the next challenge. Williamson condition and acidic benzylation using benzyl imidate are not sufficiently selective, whereas the reductive benzylation of the trimethylsilylated substrate showed greater promise. True enough, excellent selectivity was achieved by using 3 equivalents of benzaldehyde, furnishing, after further full desilylation with TBAF, the desired compound $\mathbf{2}$ in $72 \%$ yield from $\mathbf{2 2}$.

It should be stated that other less successful means in acquiring the pseudotrisaccharide backbone have been studied. Our effort at condensation of the imidate donor $\mathbf{2 0}$ with the diol $\mathbf{1 6}$ led to mixtures of inseparable regioisomers and stereoisomers, a demonstration of the known potential of the bulky 6-O-TBDPS group at enhancing $\alpha$-selectivity ${ }^{49}$. A participating moiety at
O2 of the mannosyl donor was ruled out to avoid complications that may be encountered in later reactions. Sequential dimannosylation of Kishi's triol also seemed feasible under our synthetic design, with glycosylation at the more reactive $\mathrm{O} 2$ using donor $\mathbf{2 0}$ followed by asymmetric 6-O-mannosylation with donor 15. Unfortunately, poor yields for both couplings were observed. Another procedure we have tried included the 2-Omannosylation of $\mathbf{1 9}$ with a donor already carrying the fatty acyl functionality at the primary position. While the glycosylation step worked as intended, the acyl moiety was also removed along with the TBDPS group on acid treatment intended to cleave the orthoformate function.

Synthesis of tuberculostearic acid and the $\boldsymbol{H}$-phosphonate 4 . Tuberculostearic acid was first isolated from M. tuberculosis in 1927 (ref. 50) and several methods for its synthesis have been reported $^{25,26,51-53}$. Nevertheless, an updated, shorter and more effective method for accessing this important fatty acid is still desirable. We decided to acquire the chiral carbon of tuberculostearic acid from the commercially available Roche ester (23). Tosylation of $\mathbf{2 3}$ to afford compound 24, followed by reduction with diisobutylaluminium hydride and methylene insertion by Wittig reaction furnished the olefin 25 (ref. 54; Fig. 4). The first long-chain elongation of $\mathbf{2 5}$ towards compound 26 was achieved by Grignard reaction under catalytic $\mathrm{Li}_{2} \mathrm{CuCl}_{2}$. Grubbs metathesis of olefin $\mathbf{2 6}$ with the olefinic acid $\mathbf{2 7}$ provided the $E / Z$ olefin mixture, which was exposed to palladium-catalysed hydrogenation to finally secure tuberculostearic acid (28). Accomplished in just six steps, this acquisition is the shortest synthetic preparation reported, thus far, for this compound.

Elaborations of the commercially available 3-O-benzyl-snglycerol were performed next. Under dicyclohexylcarbodiimide and 4 -(N,N-dimethylamino)pyridine, the fatty acid 28 was first condensed with the primary hydroxyl followed by stearic acid esterification at the secondary position in good yields. Cleavage of the benzyl group was achieved through hydrogenolysis and the generated alcohol was phosphorylated using $\mathrm{PCl}_{3}$, imidazole and $\mathrm{Et}_{3} \mathrm{~N}$ to afford the $H$-phosphonate 2 .

$\mathrm{Ac}_{2} \mathrm{PIM}_{6}$ assembly and final transformations. Our planned sugar assembly towards the tetramannoside 3 hinges on the chemoselective activation of a trichloroacetimidate donor in the presence of a thioglycoside acceptor ${ }^{55}$ (Fig. 5). Accordingly,
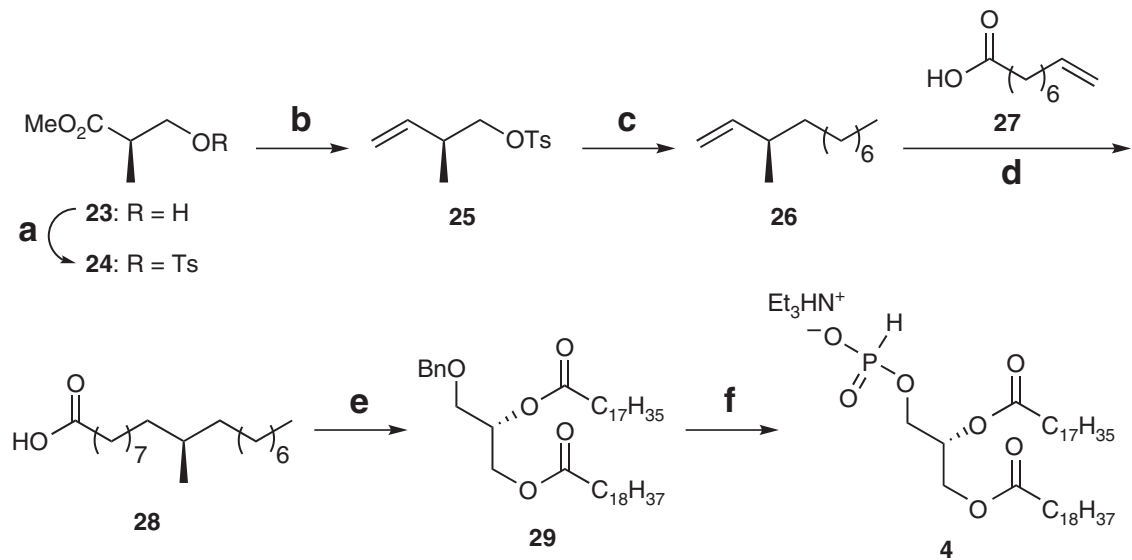

Figure 4 | Preparation of tuberculostearic acid (28) and the $\boldsymbol{H}$-phosphonate 4. Reagents and conditions: (a) $\mathrm{TsCl}_{\mathrm{S}} \mathrm{Et}{ }_{3} \mathrm{~N}, \mathrm{DMAP}, 94 \%$;

(b) (1) diisobutylaluminium hydride, $-78^{\circ} \mathrm{C}$; (2) $\mathrm{Ph}_{3} \mathrm{P}=\mathrm{CH}_{2}, 72 \%$ (two steps); (c) $\mathrm{C}_{7} \mathrm{H}_{15} \mathrm{MgBr}_{1} \mathrm{Li}_{2} \mathrm{CuCl}_{4},-78$ to $0{ }^{\circ} \mathrm{C}$, $92 \%$; (d) (1) $\mathrm{Grubbs}$ secondgeneration catalyst, $\mathrm{CH}_{2} \mathrm{Cl}_{2}$, reflux; (2) $\mathrm{H}_{2}, \mathrm{Pd} / \mathrm{C}$, 75\% (two steps); (e) (1) 3-O-benzyl-sn-glycerol, DCC, DMAP, 75\%; (2) stearic acid, DCC, DMAP, $88 \%$; (f) (1) $\mathrm{H}_{2}, \mathrm{Pd} / \mathrm{C}, 92 \%$; (2) $\mathrm{PCl}_{3}$, imidazole, $\mathrm{Et}_{3} \mathrm{~N},-10{ }^{\circ} \mathrm{C}, 69 \%$. DCC, dicyclohexylcarbodiimide; Ts, Tosyl. 

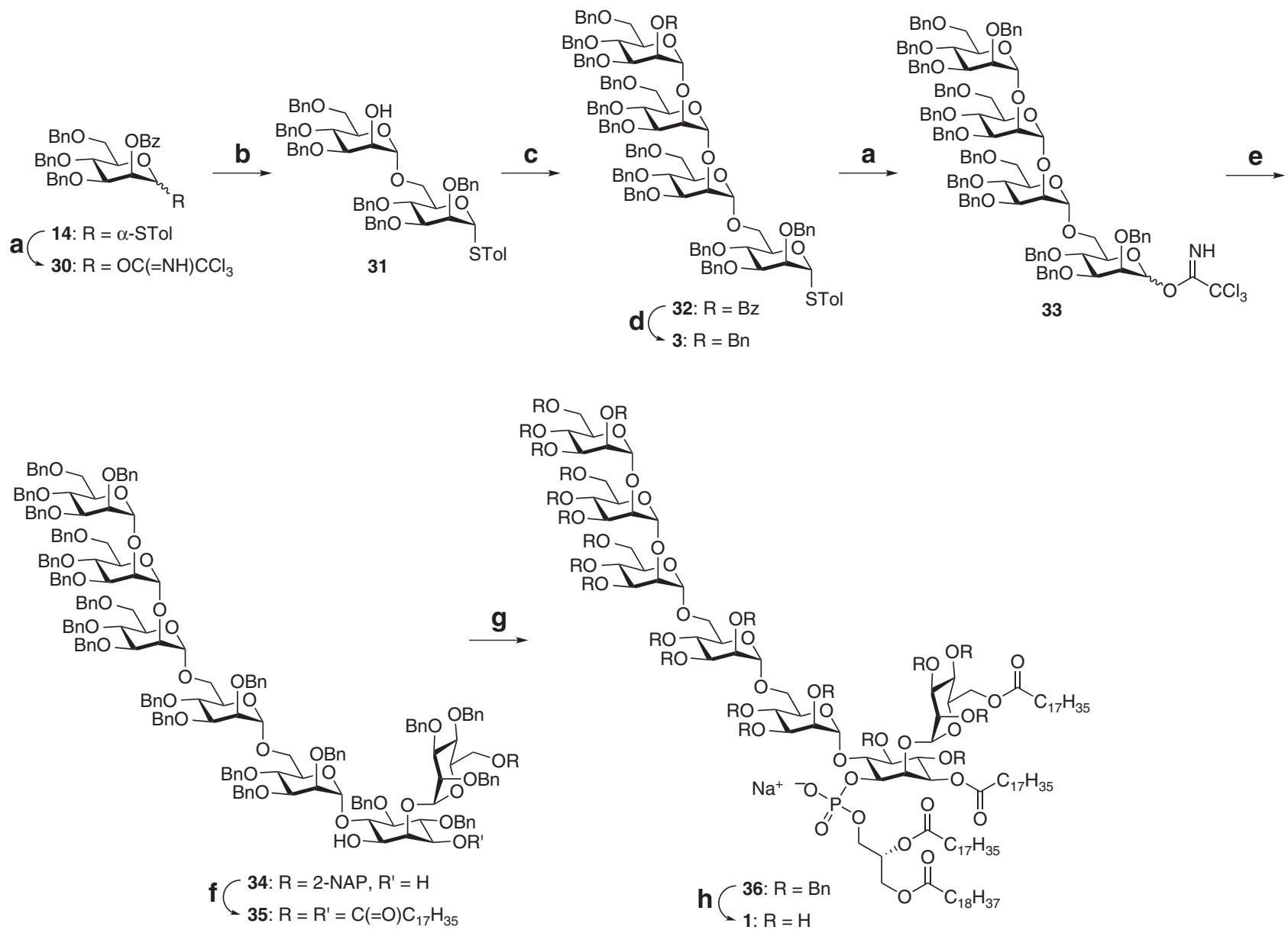

Figure 5 | Synthesis of compound 1. Reagents and conditions: (a) (1) NBS, acetone, $\mathrm{H}_{2} \mathrm{O}$; (2) $\mathrm{CCl}_{3} \mathrm{CN}$, 1,8-diazabicyclo[5.4.0]undec-7-ene, 30: 96\% (two steps), 33: $86 \%$ (two steps); (b) 8, TMSOTf, $\mathrm{CH}_{2} \mathrm{Cl}_{2},-78^{\circ} \mathrm{C}$, then, $\mathrm{NaOMe}, \mathrm{MeOH}, 87 \%$ (one pot); (c) (1) $\mathbf{3 0}, \mathrm{TfOH}_{1} \mathrm{CH}_{2} \mathrm{Cl}_{2},-60$ to $-40{ }^{\circ} \mathrm{C}$, then, $\mathrm{NaOMe}, \mathrm{MeOH}, 70 \%$ (one pot); (2) 30, $\mathrm{TfOH}, \mathrm{CH}_{2} \mathrm{Cl}_{2},-60$ to $-40^{\circ} \mathrm{C}, 74 \%$; (d) $\mathrm{BnBr}, \mathrm{NaH}, 98 \%$; (e) 2, $\mathrm{TMSOTf}^{\mathrm{Et}} \mathrm{Et}_{2} \mathrm{O}-40{ }^{\circ} \mathrm{C}, 52 \%(89 \%$ yield based on the recovered 2); (f) (1) DDQ, $\mathrm{CH}_{2} \mathrm{Cl}_{2}, \mathrm{H}_{2} \mathrm{O}, 71 \%$; (2) stearic acid, DCC, DMAP, 86\%; (g) (1) 4, pivaloyl chloride, pyridine; (2) $\mathrm{I}_{2}$, pyridine, $\mathrm{H}_{2} \mathrm{O}$; (3) DOWEX 50WX8 Na ${ }^{+}$form, 77\% from 35; (h) $\mathrm{H}_{2}, \mathrm{Pd} / \mathrm{C}, 88 \%$. TfOH, trifluoromethanesulfonic acid.

the elongation unit is formed by converting compound 14 to 30 under the usual procedures. Glycosylation of the thioglycoside $\mathbf{8}$ with 30 followed by debenzoylation in the same flask supplied the disaccharide acceptor 31 in $87 \%$ yield. Two more elongation cycles easily formed the tetramannoside 32. Knowing that the benzoate group is base-sensitive, the benzoyl-to-benzyl exchange was achieved in one step by $\mathrm{NaH}$ and benzyl bromide treatment, smoothly offering the target compound 3 in $98 \%$ yield.

With all segment backbones available, we moved forward in putting all these pieces together. The glycosylation of the pseudotrisaccharide acceptor 2 by the thioglycoside 3 , however, produced only a meager $10 \%$ yield for compound 34 despite our best efforts, prompting us to use the more reactive imidate counterpart 33 instead (see Supplementary Table 2). With $\mathrm{Et}_{2} \mathrm{O}$ as solvent and TMSOTf as activator, we eventually obtained the desired 34 in $52 \%$ yield (89\%, if the recovered acceptor is considered). The 2-NAP ether was then cleaved, which paved the way for the concurrent installation of two stearate esters at the mannosyl and the inositol units, leading to the alcohol 35. This reaction exhibited no regioselectivity issues, with $\mathrm{O} 1$ of the inositol unit spared because it experiences the highest steric hindrance among the three free hydroxyls. The attachment of the $H$-phosphonate $\mathbf{4}$ and the pseudoheptasaccharide 35 was carried out by using pivaloyl chloride, followed by iodine-mediated in situ oxidation and cation exchange, delivering the derivative 36. Global hydrogenolysis of the benzyl ethers provided the $\mathrm{Ac}_{2} \mathrm{PIM}_{6}$ construct 1 in $82 \%$ yield.

Evaluation of immunomodulatory activity. The adjuvant effects of compound 1 were examined through co-administration with ovalbumin (Fig. 6a) or tetanus toxoid (Fig. 6b) antigen in BALB/c mice. PIMs isolated from M. tuberculosis strain H37Rv ( $\mathrm{iPIM}_{1,2}$ and iPIM $_{6}$ ) and alum were also investigated in parallel for comparison. It was observed that compound $\mathbf{1}$ induced an approximately two to fourfold increase in the level of antigenspecific antibodies. The adjuvant activity of $\mathbf{1}$ is similar to the bacteria-derived PIMs and slightly lower than alum.

Furthermore, we evaluated the cytokine-producing activity of compound 1 as well as iPIM 1,2 and iPIM $_{6}$ (Fig. 6c,d). The level of interleukin- 4 and interferon- $\gamma$ was not detectable in mouse sera at $1 \mathrm{~h}$ after injection of $\mathrm{Ac}_{2}$ PIM 1 and the bacteria-derived PIMs. At $18 \mathrm{~h}$ after injection, the cytokine levels increased. Lipid and glycolipid molecules derived from $M$. tuberculosis are presented to $\mathrm{T}$ cells by $\mathrm{CD} 1$ antigen-presenting molecules, specifically CD1d ${ }^{14,56}$. Compared with the well-known CD1d-targeting $\alpha$-galactosylceramide, which can activate the invariant natural killer $\mathrm{T}$ cells and induce high levels of interleukin-4 and 

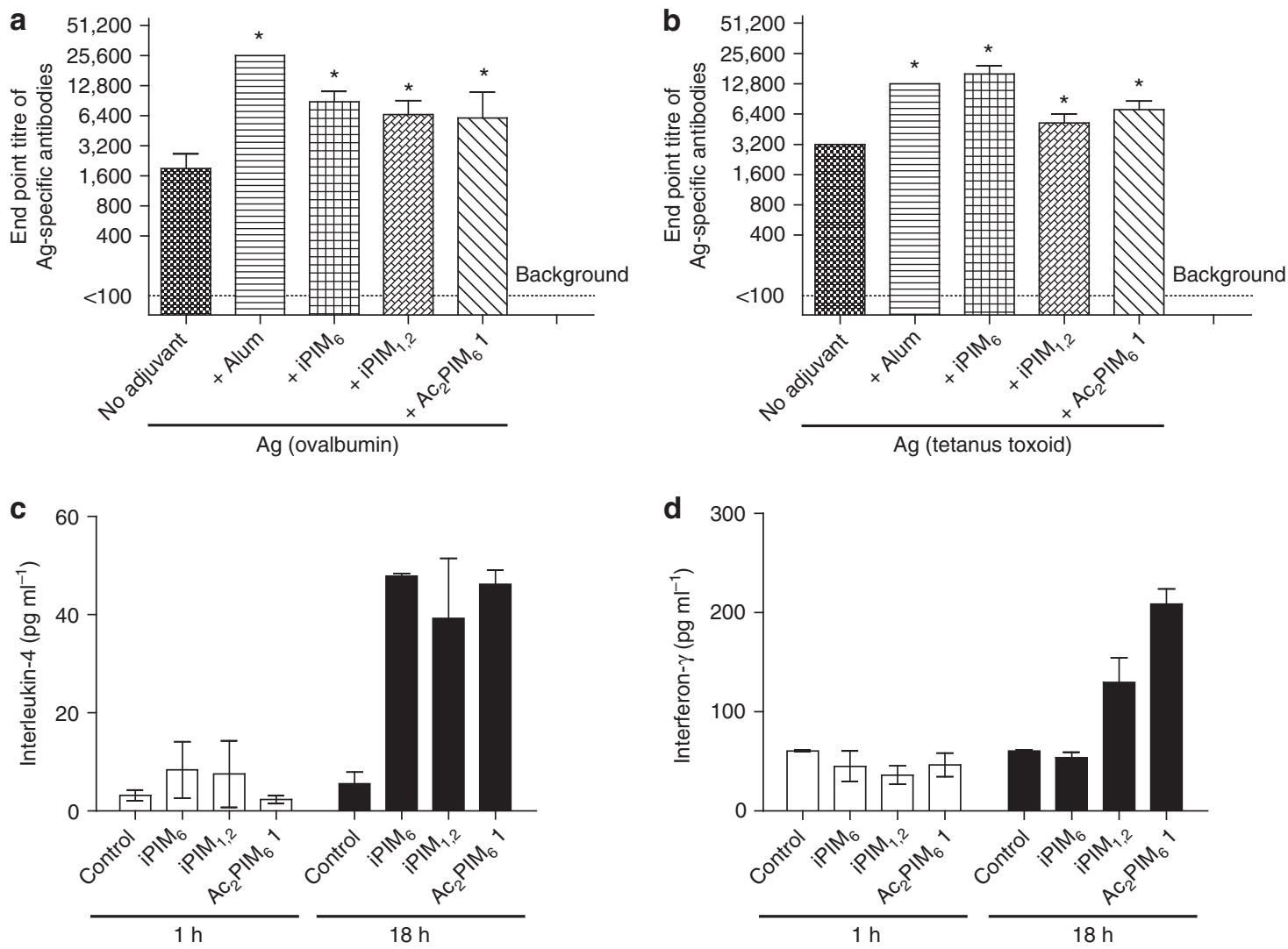

Figure 6 | Immunological evaluation in BALB/c mice. (a,b) Induction of antigen (Ag)-specific antibodies in mice immunized with ovalbumin or tetanus toxoid adjuvanted with alum or various PIMs; (c,d) secreted cytokines (interleukin- 4 and interferon- $\gamma$ ) in mice 1 and $18 \mathrm{~h}$ after injection with various PIMs (control represents injection only with PBS). Both end point antibody titres and the cytokine levels were measured by using enzyme-linked immunosorbent assay. The results displayed represent the mean +s.d.'s $(n=5)$. Data were analysed by using one-way analysis of variance, and differences were considered significant at ${ }^{\star} P<0.05$. $\mathrm{PIM}_{6}$ and $\mathrm{PPIM}_{1,2}$, isolated $\mathrm{PIM}_{6}$ and mixture of $\mathrm{PIM}_{1}$ and $\mathrm{PIM}_{2}$, respectively, from $M$. tuberculosis strain H37Rv.

interferon- $\gamma$ within $24 \mathrm{~h}$ (ref. 57), $\mathrm{Ac}_{2} \mathrm{PIM}_{6} 1$ appeared to have moderate effects.

\section{Discussion}

We have successfully developed a convenient route to synthesize an $\mathrm{Ac}_{2} \mathrm{PIM}_{6}$ construct in the form of compound $\mathbf{1}$ containing tuberculostearic acid and stearic acid as the fatty acid components. This is the first time that an $\mathrm{Ac}_{2} \mathrm{PIM}_{6}$ molecule was synthesized. Further, a novel and short synthetic route towards tuberculostearic acid was developed, with only six synthetic steps from the commercially available Roche ester and four purification stages. Our synthetic approach benefitted from the use of shared mannoside-building blocks, the carefully chosen orthogonal protecting groups and the features of the regioselective one-pot transformations from trimethylsilylated starting materials previously developed by us. The trichloroacetimidate donor types ${ }^{58}$ are vital factors in achieving the successful assembly processes. Regioselectivity and stereoselectivity were achieved through the aid of steric and stereoelectronic effects. Steric effects were also exploited in the direct desymmetrization of myo-inositol by mannosyl donors and in minimizing the number of protecting groups used in the synthesis. With practical access and functional group flexibility, the key intermediates such as the pseudotrisaccharide 2 possess good potential in supplying PIMs of different mannosylation and lipidation patterns as well. Our synthesized $\mathrm{Ac}_{2} \mathrm{PIM}_{6}$ has comparable adjuvant activity with the natural PIMs against ovalbumin and tetanus toxoid antigens and induced the production of interleukin- 4 and interferon- $\gamma$, thus, validating the immunological qualities of PIM molecules and its value in vaccine research.

\section{Methods}

Chemical synthesis. The complete experimental details and compound characterization data can be found in the Supplementary Methods. For the NMR spectra of the compounds in this article, see Supplementary Figs 4-120. The mass spectrum of the synthesized $\mathrm{Ac}_{2} \mathrm{PIM}_{6} 1$ is shown in Supplementary Fig. 121.

Materials for immunological evaluation. All $\mathrm{BALB} / \mathrm{c}$ mice were housed at the animal facility in the Institute of Cell Biology, Academia Sinica, Taiwan in accordance with the Institutional Animal Care Committee guidelines. Purified iPIM $_{1,2}$ (NR-14846) and iPIM 6 (NR-14847) were obtained through BEI Resources, National Institute of Allergy and Infectious Diseases, National Institutes of Health (USA). Ovalbumin and tetanus toxoid were purchased from InvivoGen (San Diego, CA, USA) and Adimmune Inc. (Taichung, Taiwan), respectively.

Evaluation of adjuvant activity. Five- to six-week-old female BALB/c mice were immunized with ovalbumin $(100 \mu \mathrm{g})$ or tetanus toxoid $(2 \mu \mathrm{g})$ adjuvanted with $10 \mu \mathrm{g}$ of PIM compounds $\left(\mathrm{Ac}_{2} \mathrm{PIM}_{6} 1, \mathrm{iPIM}_{1,2}\right.$ or $\left.\mathrm{iPIM}_{6}\right)$ or alum in PBS for three times at 2 -week intervals by intramuscular injection. Two weeks after the third immunization, the immunized mice were bled for antigen-specific antibody analysis.

Ovalbumin- and tetanus toxoid-specific antibodies in heat-inactivated serum were monitored with direct enzyme-linked immunosorbent assay (ELISA). The ovalbumin- or tetanus toxoid-coated plates were incubated with mouse serum in twofold serial dilutions for $1 \mathrm{~h}$. Antigen-specific IgG was monitored by using horseradish peroxidase-conjugated anti-mouse antibodies and 3,3',5,5'tetramethylbenzidine substrate (Thermo Scientific Inc). After colour development, absorbance at $450 \mathrm{~nm}$ was recorded by using a plate reader (SpectraMax M5, Molecular Device). The end point antibody titre was defined as the highest dilution of serum to produce an absorbance 2.5 times higher than the optical absorbance produced by the pre-immune serum. The background end point antibody titre was assigned as $<1: 100$. 
Evaluation of cytokine-producing activity. Five- to six-week-old female BALB/c mice were intramuscularly injected with $10 \mu \mathrm{g}$ of the PIM compounds $\left(\mathrm{Ac}_{2} \mathrm{PIM}_{6} \mathbf{1}\right.$, $\mathrm{iPIM}_{1,2}$ or $\mathrm{PIM}_{6}$ ) in PBS and bled at 1 or $18 \mathrm{~h}$ after injection (five mice per group). The cytokines in the sera were measured with sandwich ELISA using paired antiinterleukin- 4 and anti-interferon- $\gamma$ monoclonal antibodies (R\&D Systems).

Statistical analysis. The response of each mouse was counted as an individual data point for statistical analysis. Data obtained from animal studies were analysed by using one-way analysis of variance from Graphpad and differences were considered significant at $P<0.05$.

\section{References}

1. WHO. Tuberculosis factsheet $\mathrm{N}^{\circ} 104 \mathrm{http} / /$ www.who.int/mediacentre/ factsheets/fs104/en/ (2014).

2. Orme, I. M. The search for new vaccines against tuberculosis. J. Leukoc. Biol. 70, 1-10 (2001)

3. Zumla, A. I. et al. New antituberculosis drugs, regimens, and adjunct therapies: needs, advances, and future prospects. Lancet Infect. Dis. 14, 327-340 (2014).

4. Dye, C. \& Williams, B. G. The population dynamics and control of tuberculosis. Science 328, 856-861 (2010).

5. Karakousis, P. C., Bishai, W. R. \& Dorman, S. E. Mycobacterium tuberculosis cell envelope lipids and the host immune response. Cell Microbiol. 6, 105-116 (2004).

6. Flynn, J. L. \& Chan, J. What's good for the host is good for the bug. Trends Microbiol. 13, 98-102 (2005).

7. Russell, D. G. Who puts the tubercle in tuberculosis? Nat. Rev. Microbiol. 5, 39-47 (2007).

8. Hestvik, A. L. K., Hmama, Z. \& Av-Gay, Y. Mycobacterial manipulation of the host cell. FEMS Microbiol. Rev. 29, 1041-1050 (2005).

9. Bhowruth, V., Alderwick, L. J., Brown, A. K., Bhatt, A. \& Besra, G. S. Tuberculosis: a balanced diet of lipids and carbohydrates. Biochem. Soc. Trans. 36, 555-565 (2008)

10. Józefowski, S., Sobota, A. \& Kwiatkowska, K. How Mycobacterium tuberculosis subverts host immune responses. BioEssays 30, 943-954 (2008).

11. Cao, B. \& Williams, S. J. Chemical approaches for the study of the mycobacterial glycolipids phosphatidylinositol mannosides, lipomannan and lipoarabinomannan. Nat. Prod. Rep. 27, 919-947 (2010).

12. Gilleron, M. et al. Acylation state of the phosphatidylinositol mannosides from Mycobacterium bovis Bacillus Calmette Guérin and ability to induce granuloma and recruit natural killer T cells. J. Biol. Chem. 276, 34896-34904 (2001).

13. Torrelles, J. B., Azad, A. K. \& Schlesinger, L. S. Fine discrimination in the recognition of individual species of phosphatidyl-myo-inositol mannosides from Mycobacterium tuberculosis by C-type lectin pattern recognition receptors. J. Immunol. 177, 1805-1816 (2006).

14. Fischer, K. et al. Mycobacterial phosphatidylinositol mannoside is a natural antigen for CD1d-restricted T cells. Proc. Natl Acad. Sci. USA 101, 10685-10690 (2004).

15. Rojas, R. E. et al. Phosphatidylinositol mannoside from Mycobacterium tuberculosis binds $\alpha_{5} \beta_{1}$ integrin (VLA-5) on CD4 ${ }^{+} \mathrm{T}$ cells and induces adhesion to fibronectin. J. Immunol. 177, 2959-2968 (2006).

16. Guerin, M. E., Korduláková, J., Alzari, P. M., Brennan, P. J. \& Jackson, M. Molecular basis of phosphatidyl-myo-inositol mannoside biosynthesis and regulation in mycobacteria. J. Biol. Chem. 285, 33577-33583 (2010).

17. Elie, C. J. J., Verduyn, R., Dreef, C. E., van der Marel, G. A. \& van Boom, J. H. Iodinium ion-mediated mannosylations of myo-inositol: synthesis of a mycobacteria phospholipid fragment. J. Carbohydr. Chem. 11, 715-739 (1992).

18. Watanabe, Y., Yamamoto, T. \& Okazaki, T. Synthesis of 2,6-di- $O-\alpha$-Dmannopyranosylphosphatidyl-D-myo-inositol. Utilization of glycosylation and phosphorylation based on phosphite chemistry. Tetrahedron 53, 903-918 (1997).

19. Stadelmaier, A. \& Schmidt, R. R. Synthesis of phosphatidylinositol mannosides (PIMs). Carbohydr. Res. 338, 2557-2569 (2003).

20. Stadelmaier, A., Biskup, M. B. \& Schmidt, R. R. Synthesis of serine-linked phosphatidylinositol mannosides (PIMs). Eur. J. Org. Chem. 2004, 3292-3303 (2004).

21. Jayaprakash, K. N., Lu, J. \& Fraser-Reid, B. Synthesis of a key Mycobacterium tuberculosis biosynthetic phosphoinositide intermediate. Bioorg. Med. Chem. Lett. 14, 3815-3819 (2004).

22. Jayaprakash, K. N., Lu, J. \& Fraser-Reid, B. Synthesis of a lipomannan component of the cell-wall complex of Mycobacterium tuberculosis is based on Paulsen's concept of donor/acceptor "match". Angew. Chem. Int. Ed. 44, 5894-5898 (2005).

23. Ainge, G. D. et al. Phosphatidylinositol mannosides: synthesis and suppression of allergic airway disease. Bioorg. Med. Chem. 14, 5632-5642 (2006).
24. Ainge, G. D. et al. Phosphatidylinositol mannosides: synthesis and adjuvant properties of phosphatidylinositol di- and tetramannosides. Bioorg. Med. Chem. 14, 7615-7624 (2006).

25. Liu, X., Stocker, B. L. \& Seeberger, P. H. Total synthesis of phosphatidylinositol mannosides of Mycobacterium tuberculosis. J. Am. Chem. Soc. 128, 3638-3648 (2006).

26. Dyer, B. S. et al. Synthesis and structure of phosphatidylinositol dimannoside. J. Org. Chem. 72, 3282-3288 (2007).

27. Ainge, G. D. et al. Phosphatidylinositol mannoside ether analogues: syntheses and interleukin-12-inducing properties. J. Org. Chem. 72, 5291-5296 (2007).

28. Boonyarattanakalin, S., Liu, X., Michieletti, M., Lepenies, B. \& Seeberger, P. H. Chemical synthesis of all phosphatidylinositol mannoside (PIM) glycans from Mycobacterium tuberculosis. J. Am. Chem. Soc. 130, 16791-16799 (2008).

29. Ali, A., Wenk, M. R. \& Lear, M. J. Total synthesis of a fully lipidated form of phosphatidyl-myo-inositol dimannoside (PIM-2) of Mycobacterium tuberculosis. Tetrahedron Lett. 50, 5664-5666 (2009).

30. Patil, P. S. \& Hung, S.-C. Total synthesis of phosphatidylinositol dimannoside: a cell-envelope component of Mycobacterium tuberculosis. Chem. Eur. J. 15, 1091-1094 (2009).

31. Patil, P. S. \& Hung, S.-C. Synthesis of mycobacterial triacylated phosphatidylinositol dimannoside containing an acyl lipid chain at 3-O of inositol. Org. Lett. 12, 2618-2621 (2010).

32. Ainge, G. D. et al. Chemical synthesis and immunosuppressive activity of dipalmitoyl phosphatidylinositol hexamannoside. J. Org. Chem. 76, 4941-4951 (2011).

33. Ainge, G. D. et al. Synthesis and Toll-like receptor 4 (TLR4) activity of phosphatidylinositol dimannoside analogues. J. Med. Chem. 54, 7268-7279 (2011).

34. Rankin, G. M. et al. Synthesis and mass spectral characterization of mycobacterial phosphatidylinositol and its dimannosides. J. Org. Chem. 77, 6743-6759 (2012).

35. Sureshan, K. M., Shashidhar, M. S., Praveen, T. \& Das, T. Regioselective protection and deprotection of inositol hydroxyl groups. Chem. Rev. 103, 4477-4504 (2003).

36. Patil, P. S., Zulueta, M. M. L. \& Hung, S.-C. Synthesis of phosphatidylinositol mannosides. J. Chin. Chem. Soc. 61, 151-162 (2014).

37. Takahashi, H., Kittaka, H. \& Ikegami, S. Novel synthesis of enantiomerically pure natural inositols and their diastereoisomers. J. Org. Chem. 66, 2705-2716 (2001).

38. Watt, J. A. \& Williams, S. J. Rapid, iterative assembly of octyl $\alpha-1,6-$ oligomannosides and their 6-deoxy equivalents. Org. Biomol. Chem. 3, 1982-1992 (2005).

39. Wang, C.-C. et al. Regioselective one-pot protection of carbohydrates. Nature 446, 896-899 (2007)

40. Wang, C.-C., Kulkarni, S. S., Lee, J.-C., Luo, S.-Y. \& Hung, S.-C. Regioselective one-pot protection of glucose. Nat. Protoc. 3, 97-113 (2008).

41. Chang, K.-L., Zulueta, M. M. L., Lu, X.-A., Zhong, Y.-Q. \& Hung, S.-C. Regioselective one-pot protection of D-glucosamine. J. Org. Chem. 75, 7424-7427 (2010).

42. Huang, T.-Y., Zulueta, M. M. L. \& Hung, S.-C. One-pot strategies for the synthesis of the tetrasaccharide linkage region of proteoglycans. Org. Lett. 13, 1506-1509 (2011).

43. Patil, P. S., Lee, C.-C., Huang, Y.-W., Zulueta, M. M. L. \& Hung, S.-C. Regioselective and stereoselective benzylidene installation and one-pot protection of D-mannose. Org. Biomol. Chem. 11, 2605-2612 (2013).

44. Huang, T.-Y., Zulueta, M. M. L. \& Hung, S.-C. Regioselective one-pot protection, protection-glycosylation and protection-glycosylation-glycosylation of carbohydrates: a case study with D-glucose. Org. Biomol. Chem. 12, 376-382 (2014).

45. Shie, C.-R. et al. $\mathrm{Cu}(\mathrm{OTf})_{2}$ as an efficient and dual-purpose catalyst in the regioselective reductive ring opening of benzylidene acetals. Angew. Chem. Int Ed. 44, 1665-1668 (2005).

46. Wang, C.-C. et al. Synthesis of biologically potent $\alpha 1 \rightarrow 2$-linked disaccharide derivatives via regioselective one-pot protection-glycosylation. Angew. Chem. Int. Ed. 41, 2360-2362 (2002).

47. Bock, K. \& Pedersen, C. A study of ${ }^{13} \mathrm{CH}$ coupling constants in hexopyranoses. J. Chem. Soc. Perkin. Trans. 2, 293-297 (1974).

48. Duus, J. Ø., Gotfredsen, C. H. \& Bock, K. Carbohydrate structural determination by NMR spectroscopy: modern methods and limitations. Chem Rev. 100, 4589-4614 (2000).

49. Zulueta, M. M. L. et al. $\alpha$-Glycosylation by D-glucosamine-derived donors: synthesis of heparosan and heparin analogues that interact with mycobacterial heparin-binding hemagglutinin. J. Am. Chem. Soc. 134, 8988-8995 (2012).

50. French, G. L. et al. Diagnosis of tuberculous meningitis by detection of tuberculostearic acid in cerebrospinal fluid. Lancet 330, 117-119 (1987).

51. Prout, F. S., Cason, J. \& Ingersoll, A. W. The synthesis of tuberculostearic acid. J. Am. Chem. Soc. 69, 1233-1233 (1947). 
52. Schmidt, G. A. \& Shirley, D. A. A new synthesis of tuberculostearic acid. J. Am. Chem. Soc. 71, 3804-3806 (1949).

53. Roberts, I. O. \& Baird, M. S. A new short synthesis of 10-(R)-tuberculostearic acid and its enantiomer. Chem. Phys. Lipids 142, 111-117 (2006).

54. Li, H., Wu, J., Luo, J. \& Dai, W.-M. A concise total synthesis of amphidinolide T2. Chem. Eur. J. 16, 11530-11534 (2010).

55. Kaeothip, S. \& Demchenko, A. V. Expeditious oligosaccharide synthesis via selective, semi-orthogonal, and orthogonal activation. Carbohydr. Res. 346, 1371-1388 (2011)

56. De Libero, G. \& Mori, L. The T-Cell response to lipid antigens of Mycobacterium tuberculosis. Front. Immunol. 5, 219 (2014).

57. Shiozaki, M. et al. Synthesis of RCAI-172 (C6 epimer of RCAI-147) and its biological activity. Bioorg. Med. Chem. 22, 827-833 (2014).

58. Schmidt, R. R. \& Kinzy, W. Anomeric-oxygen activation for glycoside synthesis: the trichloroacetimidate method. Adv. Carbohydr. Chem. Biochem. 50, 21-123 (1994).

\section{Acknowledgements}

This work was supported by the Ministry of Science and Technology (MOST 100-2113M-001-019-MY3 and MOST 102-2628-M-001-001), National Health Research Institute (NHRI-EX103-10146NI) and Academia Sinica.

\section{Author contributions}

S.-C.H. designed the study, supervised students and staffs, and finalized the manuscript preparation. P.S.P. performed the synthesis of $\mathrm{Ac}_{2} \mathrm{PIM}_{6}$ 1. T.-J.R.C. and S.-T.Y. carried out the evaluation of immunological activity. M.M.L.Z. prepared the figures and wrote the manuscript. L.S.L. is involved in the early stages of manuscript preparation and assisted in compiling the Supplementary Information. All authors discussed the results and commented on the manuscript.

\section{Additional information}

Accession codes: The X-ray crystallographic coordinates for compounds 10 and $\mathbf{1 3}$ in this study have been deposited at the Cambridge Crystallographic Data Centre (CCDC), under deposition numbers CCDC 1040371 and CCDC 1040372, respectively. These data can be obtained free of charge from the CCDC via www.ccdc.cam.ac.uk/data_request/cif.

Supplementary Information accompanies this paper at http://www.nature.com/ naturecommunications

Competing financial interests: The authors declare no competing financial interests.

Reprints and permission information is available online at http://npg.nature.com/ reprintsandpermissions/

How to cite this article: Patil, P. S. et al. Total synthesis of tetraacylated phosphatidylinositol hexamannoside and evaluation of its immunomodulatory activity. Nat. Commun. 6:7239 doi: 10.1038/ncomms8239 (2015).

(c) (i) This work is licensed under a Creative Commons Attribution 4.0 International License. The images or other third party material in this article are included in the article's Creative Commons license, unless indicated otherwise in the credit line; if the material is not included under the Creative Commons license, users will need to obtain permission from the license holder to reproduce the material. To view a copy of this license, visit http://creativecommons.org/licenses/by/4.0/ 